\title{
КОНЦЕПТУАЛЬНЫЕ НАПРАВЛЕНИЯ ВЛИЯНИЯ ТЕХНОЛОГИЧЕСКОГО РАЗВИТИЯ НА СОСТОЯНИЕ ОБРАЗОВАТЕЛЬНОЙ СРЕДЫ ВЫСШЕГО УЧЕБНОГО ЗАВЕДЕНИЯ
}

\author{
(C) 2021 Зотова Елизавета Александровна \\ старший преподаватель, Высшая школа производственного менеджмента \\ Санкт-Петербургский политехнический университет Петра Великого, Россия, Санкт-Петербург \\ E-mail: zotova@spbstu.ru
}

(C) 2021 Калинина Ольга Владимировна

доктор экономических наук, директор, Высшая школа производственного менеджмента Санкт-Петербургский политехнический университет Петра Великого, Россия, Санкт-Петербург E-mail: ovkalinina@spbstu.ru

Состояние образовательной среды как основы формирования человеческого капитала образовательной организации для целей инновационного развития зависит от технологического прогресса (технологического развития), международной научной конъюнктуры и социально-экономических факторов. При этом влияние международной научной конъюнктуры и социально-экономических факторов крайне медленное и условно постоянное [1], а технологический прогресс влияет сильно и быстро, что доказала быстрая технологическая трансформация, вызванная пандемией COVID-19. Соответственно, важной задачей является понимание и математическое описание процесса влияния технологического прогресса (технологического развития) на состояние образовательной среды, что в конечном итоге результируется во влиянии на каждую образовательную организацию в целях ее инновационного развития. В данной статье представлен обзор основного базиса исследований в области влияния технологического развития на состояние образовательной среды высшего учебного заведения и сформирована концептуальная модель данного влияния.

Ключевые слова: технологическое развитие, образовательная среда, высшее учебное заведение, информационная среда.

Для выявления концептуальных направлений изменения образовательной среды под влиянием технологического прогресса, с учетом проблемы широты распространения информации, был проведён литературный обзор, в котором задействованы как отечественные источники, так и материалы зарубежных исследований со всего мира.

Первый блок проанализированной литературы связан с вопросами ограниченности использования информационных технологий и распространения информации. Многие ученые выделяют и анализируют различные причины данной проблематики, например, низкий уровень доходов в развивающихся странах, который не позволяет малообеспеченным слоям населения приобретать и использовать новые средства связи и информационные технологии, и нехватка базовых навыков для их использования.

Авторы Lambrechts и Sinha (2019) [2] утверждают, что цифровой разрыв негативно влияет на социально-экономический рост, особенно на развивающихся рынках. Снижение ограничения доступа к Интернету или его отсутствия и сокращение числа отключенной от сети доли населения во многих развивающихся странах не получают того приоритета неотложности, которого оно заслуживает, и его важность часто недооценивается. Развитые страны не всегда осведомлены о дополнительных проблемах, с которыми ежедневно сталкиваются развивающиеся страны, хотя эти проблемы могут существовать в меньшей степени, в той или иной форме, и в развитых странах. Такие проблемы, как доступность широкополосного интернета, измеряемая по валовому внутреннему продукту на душу населения, отсутствие инфраструктуры для распространения интернета, проблемы регулирования, некомпетентность в управлении затрудняют доступность и распределение интернета на развивающихся рынках. Авторы также исследуют многочисленные дополнительные проблемы, возникающие в данной связи (например, связанные с вопросами инклюзив- 
ности), а также дополнительные проблемы, которые напрямую не связаны с технологиями, но серьезно влияют на доступность Интернета и интеграцию решений последней мили в развивающихся странах, что является важным вкладом в преодоление цифрового разрыва на развивающихся рынках.

Ученые Billon, Crespo и Lera-Lopez (2020) [3] исследуют, влияет ли наличие неравенства в образовании на страновом уровне на использование Интернета. Также изучается, в какой степени эти последствия зависят от уровня экономического развития стран. Для анализа используется набор данных по 69 странам с высоким и средним уровнем доходов за период 2005-2015 гг. В ходе исследования была обнаружена отрицательная взаимосвязь между использованием Интернета и неравенством в образовании для всей выборки. Результаты подтверждают, что, помимо уровня образования и других социально-экономических переменных, распределение формального образования среди граждан внутри страны также важно для объяснения использования Интернета. Это распределение влияет на использование Интернетом даже в большей степени в странах со средним уровнем дохода, чем в странах с высоким уровнем дохода. В отличие от положительного влияния уровня образования, активно изученного в академической литературе (см., например, [1]), наличие неравенства в образовании внутри страны отрицательно влияет на использование Интернета. Это исследование демонстрирует относительное влияние структуры образования в странах на объяснение динамики использования сети Интернет.

James (2020) [4] доказал, что из-за низкой доступности и нехватки навыков особенно трудно обеспечить пользование Интернетом в сельских районах развивающихся стран. Но начинает появляться ряд многообещающих альтернатив. Они в основном предназначены для того, чтобы предоставить доступ в Интернет тем, кто не является пользователями, то есть лицам, которые фактически не контактируют с технологией напрямую. Такие люди составляют основную часть сельского населения в большинстве развивающихся стран. Существуют две возможности: одна включает посредничество на расстоянии (смешивание), а другая - на близком расстоянии (например, через Интернет-киоски). Для меньшинства тех, кто действительно может пользоваться Интернетом, затраты могут быть уменьшены за счет сочетания общественных институтов и технических средств совместного использования. В настоящее время есть множество примеров, когда Интернет лучше используется людьми с низким уровнем доходов, отсутствием навыков и другими особенностями сельских районов в бедных странах. Однако в настоящее время эти примеры разбросаны по странам и концептуально обычно не связаны друг с другом. Однако автор утверждает, что соответствующие механизмы доступа в Интернет могут быть полезно проанализированы с помощью простой структуры в виде древовидной диаграммы. В большей части данное исследование адресовано политическим структурам, которые стремятся донести преимущества информационных технологий до менее обеспеченных домохозяйств в своих странах.

Sintas, Lamberti и Sukphan (2020) [5] анализируют цифровой разрыв в Таиланде, который также является развивающейся страной. Исследуется, как концепции теории ресурсов и присвоения объясняют разнообразие использования Интернета. Было обнаружено, что возможности доступа к компьютеру и Интернету являются основными движущими силами самого использования Интернета, а также что их влияние зависит от ресурсов отдельных лиц и социальных категорий (в частности, пола, возраста и образования), что приводит к появлению мобильных (более молодые, более образованные, городские женщины) и традиционных классов пользователей (пожилые, менее образованные, замужние, сельские жители). Также движущие силы разнообразия использования Интернета могут быть связаны с теорией поколений, что свидетельствует о необходимости переключить фокус исследований с домашних хозяйств на отдельных лиц даже в менее развитых странах.

Таким образом, анализ литературного блока, посвященного ограниченности использования информационных технологий и распространения информации, позволяет говорить о влиянии широты распространения информации и информационной среды в целом на уровень грамотности населения, количество учащихся и в следствие на уровень образования в стране. Далее необходимо рассмотреть зависимость качества образования и его составляющих от развития информационной среды. Также в литературе активно рассматривается тема сложности 
новых подходов развития образования в условиях недоступности информации в развивающихся странах.

Авторы Burbules, Fan и Repp (2020) [6] утверждают, что достижение качественного образование как цель связано с некоторыми общими тенденциями, влияющими на образование в информационную эпоху. Бесспорно, образование является ключом к будущему качеству человеческой жизни и устойчивости мира. Образование трансформируется как в формальном, так и в неформальном контексте обучения с помощью новых цифровых технологий. Некоторые из подобных инноваций (например, образовательные цели и задачи; образовательная экология и контексты обучения; процессы обучения) и то, как они меняют образовательную среду, подробно рассматриваются в статье. Между тем, нельзя не сказать о некоторых потенциальных рисках и недостатках технологических инноваций. С точки зрения устойчивого развития создаётся большой потенциал реформы образования, но возможность его реализации будет только в случае готовности переосмысления и даже отказа от некоторых из традиционных способов ведения дел в образовании.

Основная цель исследования авторов Chiu, Liang и Tsai (2016) [7] состояла в том, чтобы изучить роль образования и опыта поиска в Интернете в убеждениях студентов, связанных с Интернетом, при поиске информации. Китайская версия Интернет-специфического эпистемологического вопросника (C-ISEQ) использовалась для оценки убеждений участников относительно неопределенности, соучастия и источника Интернет-знаний, а также для их обоснования. Всего было опрошено 1070 студентов. Иерархический регрессионный анализ был использован для анализа взаимосвязи образования и опыта поиска в Интернете с убеждениями учащихся. Эффект взаимодействия между сроком образования и опытом поиска в Интернете был задействован в регрессионной модели для изучения его корреляций с представлениями учащихся. Результаты показали, что количество лет обучения положительно коррелирует с неопределенностью и источником Интернет-знаний, а также с их обоснованием. Кроме того, опыт поиска в Интернете имеет отрицательную связь с неопределенностью, сложностью и источником знаний в Интернете; тем не менее, это положительно коррелировало с обоснованием знаний через
Интернет. Эффект взаимодействия количеством лет получения образования и опытом поиска в Интернете был в значительной степени связан с обоснованием знаний, основанных на Интернете. Результаты этого исследования подчеркивают важность роли информационной функции Интернета в развитии образования.

Исследование Chang, Lee и Ryu (2020) [8] направлено на разработку образовательной интернет-программы по медицинской информации, а также на изучение осуществимости программы и предварительных результатов. Было проведено оценивание осуществимости и влияния образовательной программы с использованием одногруппового предварительного и последующего тестирования через оценку обобщенного уравнения. Одиннадцать пожилых людей участвовали в занятиях с 25 января по 22 февраля 2019 года. Результаты по каждому компоненту программы в ходе предварительного исследования (компьютерные/веб-знания ( $\mathrm{p}<0,001)$, отношение к информации о здоровье в Интернете ( $\mathrm{p}=0,002)$; показатель грамотности в области электронного здравоохранения (р <0,001); показатели эффективности поиска ( $\mathrm{p}<0,001)$ и уровень понимания медицинской информации в Интернете $(\mathrm{p}=0,002))$ показали значительное улучшение при последующем тестировании. Это пилотное исследование показывает, что образовательная программа на основе теории поведения по использованию медицинской информации из сети Интернет является эффективным способом повышения уровня грамотности пожилых людей в области электронного здравоохранения.

Asongu, Orim и Nting (2019) [9] провели анализ взаимосвязи между неравенством, информационными и коммуникационными технологиями (ИКТ) и инклюзивным образованием, что способствовало установлению пороговых значений неравенства, которые не должны быть превышены, чтобы ИКТ могли способствовать инклюзивному образованию в 42 странах Африки к югу от Сахары в период 2004-2014 гг.. Эмпирические данные основаны на обобщенном методе моментов. Установлены следующие выводы: во-первых, коэффициент Джини (индекс концентрации доходов) и индекс Аткинсона (индекс социального неравенства), равные 0,400 и 0,625 соответственно, являются порогами неравенства доходов, которые нельзя превышать, чтобы проникновение Интернета положительно 
повлияло на инклюзивное образование. Во-вторых, коэффициент Джини, индекс Аткинсона и коэффициент Пальмы (альтернатива коэффициента Джини), равные 0,574, 0,676 и 9,000 соответственно, являются пороговыми значениями неравенства доходов, превышение которых препятствует положительному влиянию на инклюзивное образование. Таким образом, авторами был получен следующий вывод: для того, чтобы технологическое развитие и технологический прогресс способствовали инклюзивному образованию в странах, включенных в выборку, не следует превышать установленные пороги неравенства.

Несмотря на влияние технологий социальных сетей для совместного создания знаний, недавнее исследование Bouton, Bar Tal и Asterhan (2020) [10] в средних школах показывает, что учащиеся используют эти инструменты в основном для обмена знаниями, связанными с обучением. Данные результаты распространяются на высшие учебные заведения, также авторы приводят результаты двух исследований, которые отображают характеристики самостоятельного использования студентами социальных сетей в учебных целях, в программах бакалавриата (размер выборки составил $\mathrm{N}=264$ ) и педагогических колледжах ( $\mathrm{N}=449)$. Обмен знаниями, касающимися образовательных процессов, был предсказан позитивным отношением к совместному использованию и коллективистскими ценностными ориентациями, мотивированным в целом просоциальными причинами, реже в конкурсных программах обучения. Использование общих материалов было связано с достижением целей по избеганию производительности и более низким средним баллом.

Авторы Zhao, Zhong и Zhou (2020) [11] показали, что воспитание инновационных талантов и создание студенческих предпринимательских команд являются основными образовательными целями университетов, являющимися важной частью национальной инновационной системы. Предпринимательские команды студентов университетов представляют собой атрибут высоких технологий и уникальное преимущество знаний. Взяв в качестве объекта исследования предпринимательские команды студентов университетов, было распространено в общей сложности 500 копий анкеты и извлечено 386 действительных копий, с показателем поиска 77\%. С помощью анкетного опроса выявлялись осве- домленность, эмоции и желание учащихся к инновациям в образовании. Результаты исследования показали, что инновационное образование имеет значительную положительную корреляцию с сотрудничеством; сотрудничество показывает высокую положительную корреляцию со стратегическими инновациями; также инновационное образование обнаруживает особенно положительные корреляции со стратегическими инновациями. Согласно результатам исследования, авторы выдвигают ряд предложений, основывающихся на том, что предпринимательские группы студентов китайских университетов смогут получить преимущество технологических инноваций, применив возможности инфраструктуры широкополосных и беспроводных сетей и разработав инновационные приложения и модели предпринимательства.

В статье авторов Tavares, Laranjeiro и Ferraz (2016) [12] исследовалось расширение понимания дистанционного обучения в высшем образовании с использованием Интернета. На основе обзора литературы была составлена методология и проведено расширенное исследование инструментов поддержки, процессов взаимодействия и коммуникации, методологий планирования, типов контента и инструментов оценки в дистанционном образовании с использованием Интернета. Результаты анализа и триангуляции данных показывают, что дистанционное образование с использованием Интернета может принимать различные типологии, использовать различные процессы взаимодействия и коммуникации и различные технологические инструменты поддержки и оценки, отвечая определенным целям и потребностям учащихся в обучении.

Российскими учеными также написано большое количество работ, посвященных влиянию технологического прогресса, информационной среды (в частности, дистанционного обучения) на показатели деятельности и развития образовательной организации. При этом в работах российских ученых особый акцент идет на изучение психологического состояния участников образовательной среды вследствие процесса цифровизации образования.

Например, авторы Богданов и Коростылев (2018) [13] рассматривают семь психологических типов студентов, каждый из которых может быть детализирован в зависимости от поставленных задач до нужной глубины. Был пред- 
ложен подход для оценки на основе КPI, учитывающий применение, настройку и развитие системы интеллектуальных уведомлений с точки зрения API интерфейсов LMS (англ. Learning management system - Система управления обучением. Предлагаемый авторами подход может помочь эксперту в области электронного обучения определить отклонения в учебном процессе, использовать индивидуальные траектории обучения.

Данилова и Холина (2015) [14] рассматривают проблемы использования дистанционных технологий и их сочетание с традиционными методами в процессе обучения. Авторы уделяют внимание образовательному, психологическому, социальному аспектам, анализируя достоинства и недостатки обучения при применении дистанционных технологий. Исследователи отмечают, что «появление интерактивных информационных сетей, воплощающих различные способы коммуникации, которые впервые объединили в одной системе письменные, устные и аудиовизуальные способы общения, по своей революционности сопоставимо с появлением в Греции ... алфавита».

Хрянин и Швецов (2017) [15] рассматривают проблему применения программных агентов для оценки психологического состояния студентов в системе дистанционного обучения. Автору проверяют гипотезу, что чем лучше психологически материал подходит обучаемому, тем быстрее и качественнее он будет усвоен. Кратко описана реализация системы дистанционного обучения: схема взаимодействия агентов, основные таблицы БД, реализация серверной и пользовательской частей. Описываются метод и алгоритм определения перцептивной модальности обучаемого в ходе психологического тестирования. Использованы статистические методы для предсказания вероятности входа в систему обучаемым (на основе данных статистики). Предложены весовые коэффициенты частоты использования системы дистанционного обучения обучаемыми для принятия решений агентом определения психологического состояния. Эксперимент показал, что использование агента, определяющего тип восприятия студента, повышает эффективность дистанционного обучения. С контрольным тестом справились более $61 \%$ обучаемых, а усложненную задачу решили более половины группы (около 42\% и 12\% в контрольной группе соответственно), что до- казывает необходимость разработки автоматического алгоритма подбора материала.

Автором Марчук (2013) [16] изучалась специфика среды взаимодействия и особенности организации учебной информации в отсутствие прямого контакта учащегося с педагогом, которые определяют психолого-педагогические особенности дистанционного обучения. Автор отмечает, что психолого-педагогические особенности дистанционного обучения складываются из специфики виртуальной среды, особенностей взаимодействия в этой среде и организации информации в условиях виртуального взаимодействия. Эти особенности предопределяют организацию данной формы обучения, применяемые средства и методы, а также формы контроля и оценочную деятельность.

Козлова (2013) [17] посвятила свое исследование организации процесса обучения с применением дистанционной формы обучения, дав анализ основных видов и четырех моделей дистанционного обучения и показав отличия дистанционного обучения от традиционного. Доказано, что эффективность каждой из рассмотренных моделей дистанционного обучения зависит от организации и методического качества используемых материалов, а также мастерства педагогов, участвующих в этом процессе.

В исследовании Шелудько (2015) [18] были выделены основные факторы, влияющие на готовность преподавателей разных возрастных групп к внедрению дистанционных образовательных технологий в учебный процесс, а также выявлены психологические проблемы, возникающие у преподавателей в процессе. Автор считает, что отношение преподавателей разных возрастных групп к дистанционному обучению является на сегодняшний день одним их ключевых факторов, влияющих на успешность внедрения в учебный процесс дистанционных образовательных технологий, однако на данный момент психолого-педагогическое обоснование этого процесса не разработано на должном уровне. Но дальнейшее изучение и более детальная проработка данной проблематики могут послужить основой для создания единого подхода к процессу преодоления психологических трудностей преподавателей.

Деевой (2013) [19] рассматриваются психолого-педагогические аспекты подготовки бакалавров в ходе реализации стандартов нового поколения и особенности организации само- 
стоятельной работы студентов в дистанционной образовательной среде, раскрываются основные этапы процесса подготовки бакалавров в условиях дистанционного обучения. Автор пришел к выводу, что при реализации дистанционного обучения в вузе важную роль играет комплекс психолого-педагогических условий подготовки бакалавров к получению образования по стандартам нового поколения.

Петухова (2014) [20] в одной из первых отечественных работ, посвященных особенностям организации обучения в модульной объектноориентированной динамической учебной среде Moodle, исследует основные психологические проблемы работы в данной системе, которые были подразделены на общие и индивидуальные. Предлагаются пути решения данных проблем в ходе реализации психологопедагогического сопровождения. Автор считает, что на начальном этапе необходима диагностика затруднений у студента при работе с тем или иным курсом в системе. Далее нужно составить совместно со студентом индивидуальную траекторию работы. Также автор указывает, что необходимо проводить тренинги по написанию электронного письма, которые включали бы в себя основные правила написания письменных текстов, информацию о стиле деловой переписки и т.д.

Алещенко, Трембач В. И Трембач Т. (2018) [21] рассматривают электронные системы дистанционного обучения, исследуя возможности применения когнитивных механизмов для развития технологий образования. Авторами представлен пример разработки и использования учебного ресурса для изучения иностранного языка в техническом ВУЗе. Электронный курс создан в системе дистанционного обучения Moodle. Показан результат тестирования студентов после изучения каждой темы. Показаны структура аппаратно-программных модулей для формирования концептов -представлений из чувственных образов объектов и явлений действительности. Представлены аппаратнопрограммные модули, которые необходимы для формирования концептов-представлений из множества отображений управляющих воздействием, а также демо пример формирования концептов -сценариев и фрагмент базы знаний, содержащий сформированный концептсценарий. В итоге, авторами было доказано, что использование системы дистанционного обуче- ния Moodle действительно позволяет обучающимся полноценно отрабатывать текущий материал изучаемого курса.

Яницкий (2019) [22] в своей работе рассматривает вызовы современного информационного общества системе образования. Анализируются изменения роли субъектов образовательного процесса в обществе знаний, ставится цель раскрыть характеристики психологических эффектов дистанционного образования, определяющих оценку целесообразности, и оптимальную степень цифровизации конкретных образовательных программ. Особенно важным моментом, по мнению автора, является изменение пространственно-временных характеристик их межличностного взаимодействия, «обезличивание» и виртуализация общения, связанные с использованием средств электронной образовательной коммуникации. Результаты исследования свидетельствуют о нецелесообразности полного перехода на цифровое образование. Наиболее важным психологическим аспектом цифрового образования является принципиальное изменение характера коммуникаций субъектов образовательного процесса, определяющее его позитивные и негативные эффекты.

Исследование Ахмадиевой (2018) [23] посвящено актуальной теме использования инновационных подходов в системе высшего образования. Автор отмечает, что очное и дистанционное виды обучения должны различаться, но фундаментальных исследований природы этих различий практически нет. Более того, активно внедряя дистанционное обучение, часто закрывают глаза на его недостатки. Подробно описаны возникающие в процессе дистанционного обучения организационные сложности, связанные с каналом связи. Проанализировано психологическое состояние участников образовательного процесса, сталкивающихся с организационными сложностями в процессе дистанционного обучения. В качестве психолого-педагогических сложностей реализации дистанционного обучения в системе высшего образования выделены проблемы, возникающие при организации занятий, в том числе при организации коммуникации «преподаватель - студент», при контроле посещаемости, при проведении промежуточной аттестации.

Чванова и Киселева (2017) [24] доказали, что самое большое опасение у студентов в процессе реализации дистанционного образования вызывает отсутствие непосредственного контакта 
с преподавателем (50,25\%), ненадежность интернета (35,5\%), необходимость высокой степени самоорганизации $(18,75 \%)$.

Кармановский (2011) в своем исследовании [25] отмечает, что стереотипность преподавания и оценки качества учебной деятельности в рамках дистанционной технологии обучения тормозит формирование данного процесса. Клименских и коллеги (2018) в своем исследовании [26] пришли к выводу о том, что на успех студента в онлайн-курсе оказывает влияние высокий уровень его мотивации, ответственности, самоконтроля, а также общего показателя интеллекта. Для достижения успеха в онлайнобучении нужно быть психологически готовым, «сознательным» студентом со сформированной внутренней мотивацией.

В работе [27] авторы Барбашина и Гуляевская (2019) отмечают, что дистанционное обучение обладает высокой привлекательностью, которая во многом обусловлена его доступностью для тех, кто не может по каким-либо причинам участвовать в традиционном образовательном процессе. Также в исследовании показаны основные проблемы данного процесса, а именно: психологическая неготовность, неумение распоряжаться временем, отсутствие мотивации, дефицит коммуникации между студентами, отсутствие личных постоянных контактом с преподавателями. Для решения данных проблем были предложены способы их минимизации: постоянная двусторонняя связь между преподавателями и студентами, стимулирование и поддержка общения между студентами, проведение очных встреч студентов и преподавателей, дублирование учебной и организационной информации.

Фадеев (2017) в работе [28] рассматривает проблемы, возникающие в ходе развития образовательного процесса, обусловленные как новыми возможностями современных информационных технологий, так и потребностями общества в доступности образования самым широким слоям населения. Такие проблемы классифицированы по двум основаниям: организационные и психологические, проведен их обзор и классификационная группировка, показаны «болевые точки» дистанционного образования, что дает возможность определения путей решения указанных проблем на основе анализа причин их возникновения. Также автор указывает, что не ставил целью работы выискивать недостатки, принижать достоинства дистан- ционного образования. Наоборот, по мнению автора, в дистанционном образовании видна реальная возможность реализовать систему всеобщего непрерывного образования, приобщить любого жителя страны к «вселенной знаний».

За 2020-2021 гг. было выпущено большое количество российских и зарубежных исследований, посвященных изменениям в сфере применения информационных технологий в образовании, вызванных распространением вируса COVID-19.

В условиях кризиса COVID-19 традиционное обучение внезапно изменилось на цифровое обучение, что создало проблемы и студентам, и преподавателям. Авторы Zheng, Khan и Hussain (2020) [29] утверждают, что во время пандемии COVID-19 влиянию личностных факторов на студенческие социальные сети не уделялось должного внимания. В этом исследовании изучается взаимосвязь между проактивной личностью и социальным капиталом посредством основных механизмов (таких как самоэффективность в Интернете и качество онлайн-взаимодействия), во время первой волны пандемии COVID-19. Кроме того, это исследование также направлено на изучение регулирующей роли воспринимаемой социальной поддержки в связи между проактивной личностью и самоэффективностью в Интернете, а также между проактивной личностью и качеством онлайн-взаимодействия. Для исследования использовались инструменты онлайн-опроса для сбора данных от 332 респондентов, включая студентов и учителей из Исламабада, федеральной столицы Пакистана. Результаты анализа свидетельствуют о том, что проактивная личность студентов укрепляет их социальный капитал за счет качества онлайнвзаимодействия во время пандемии COVID-19.

По состоянию на 2021 г. образовательные учреждения по всему миру до сих пор сталкиваются с проблемами тяжелого острого респираторного синдрома, вызванного COVID-19. Онлайн-обучение проводится, чтобы избежать личного контакта в чрезвычайной ситуации, и студенты вынуждены адаптироваться к новым ролям обучения с помощью информационных технологий. Однако доступ к ресурсам онлайнобучения и их связь с удовлетворением учащихся в условиях COVID-19 имеют решающее значение для эффективности процесса обучения. Для изучения данной проблематики в первой половине июня 2020 года авторами Qazi et 
al. (2020) [30] было проведено кросс-секционное исследование среди 320 студентов в Пакистане и Брунее с использованием заранее определенного вопросника. Данные были проанализированы с помощью пакета статистических программ для социальных наук (SPSS). Учеными было установлено, что существует взаимосвязь между удовлетворенностью студентов и доступом к онлайн-обучению и его использованием. Результаты опроса показывают, что брунейцы более удовлетворены (50\%) использованием онлайн-обучения в условиях изоляции, чем пакистанцы (35,9\%). Проживание в городской местности по сравнению с сельской местностью также является важным фактором, способствующим удовлетворённости доступом и использованию онлайн-обучения как для брунейцев, так и для пакистанцев. Результаты корреляционного анализа, проведенного авторами, показывают, что факторы доступа и использования онлайн-обучения на фоне COVID-19 были положительно связаны с удовлетворенностью обеих групп населения на фоне пандемии COVID-19. Однако брунейцы больше удовлетворены доступом в Интернет $(\mathrm{r}=0,437, \mathrm{P}<0,000)$ и доступностью гаджетов ( $\mathrm{r}=0,577, \mathrm{P}<0,000)$ по сравнению с пакистанцами $(\mathrm{r}=0,176, \mathrm{P}<0,050)$ и $(\mathrm{r}=0,152$, $\mathrm{P}<0,050)$ соответственно. Исследование доказало, что правительству и другим политическим группам во всем мире крайне важно решить проблему доступа и использования ресурсов онлайн-обучения для своего населения в условиях пандемии.

Вопрос влияния дистанционного образования на студентов, и его отражение на их психологическом состоянии был затронут во многих научных статьях и трудах различных ученых. В большинстве исследований авторы отмечают, что у дистанционного обучения если как плюсы, так и минусы, касаемо его психологического влияние на студентов. Однако, большее внимание в современных работах уделяется проблемам и минусам дистанционного образования, чтобы найти способы их минимизации, а также понять, стоит ли оставлять такой формат как основной после пандемии. Факторами, которые оказывают такое воздействие, в большинстве случаев выступают: отсутствие хорошего технического оснащения и качественного взаимодействия с преподавателями и одногруппниками, а также проблема с личной самоорганизацией у студентов.
Например, в исследовании Горбатенко (2020) [31] был проведен социологический опрос среди студентов нескольких высших учебных заведений. Опрос показал следующие результаты: уровень организации дистанционного обучения не устраивал $81 \%$ опрошенных, $71 \%$ студентов считают неудобной организацию времени в период удаленного обучения и переход на удаленное обучение, у 59\% респондентов не появилось больше свободного времени для общения с близкими. Автор утверждает, что в период массового «старта» практики дистанционного обучения, большинство опрошенных было не удовлетворено качеством предоставляемого администрациями университетов удаленного образования, что, в свою очередь, сказывалось на их физическом и психологическом состоянии.

В работе Олейник и коллег (2020) [32] описаны результаты эмпирического исследования в форме анкетирования, которые свидетельствуют о том, что $60 \%$ студентов испытывают проблемы в данных условиях, 55\% - боятся не сдать сессию, многие сталкиваются с техническими проблемами, большинство нуждается в живом очном общении, что свидетельствует о начальном этапе процесса адаптации студентов к онлайн обучению с применением дистанционных образовательных технологий.

В исследовании Соколовской (2020) [33] выявлено, что образовательная среда с низким уровнем качества (отсутствием электронного оборудования на самоизоляции, необходимого для обеспечения дистанционного обучения), и неотлаженными контактами с преподавателями и одногруппниками отрицательно влияет на некоторые составляющие удовлетворенности дистанционным образованием студентов.

Бахтина и Марковский (2020) также доказали [34], что основная сложность в реализации дистанционного обучения студентами и освоении новой информационно-образовательной среды заключается в особой организации собственного времени.

В статье [35] ее автор Мукова (2020) выделяет главную субъективную проблему дистанционного образования - слабый контроль при оценке знаний. В итоге анализа данной проблемы автор выделяет 4 вывода в отношении психологического состояния участников образовательного процесса: 1) каждый субъект стремится к своей цели: студент - к получению диплома, преподаватель - зарплаты, руководство вуза - финан- 


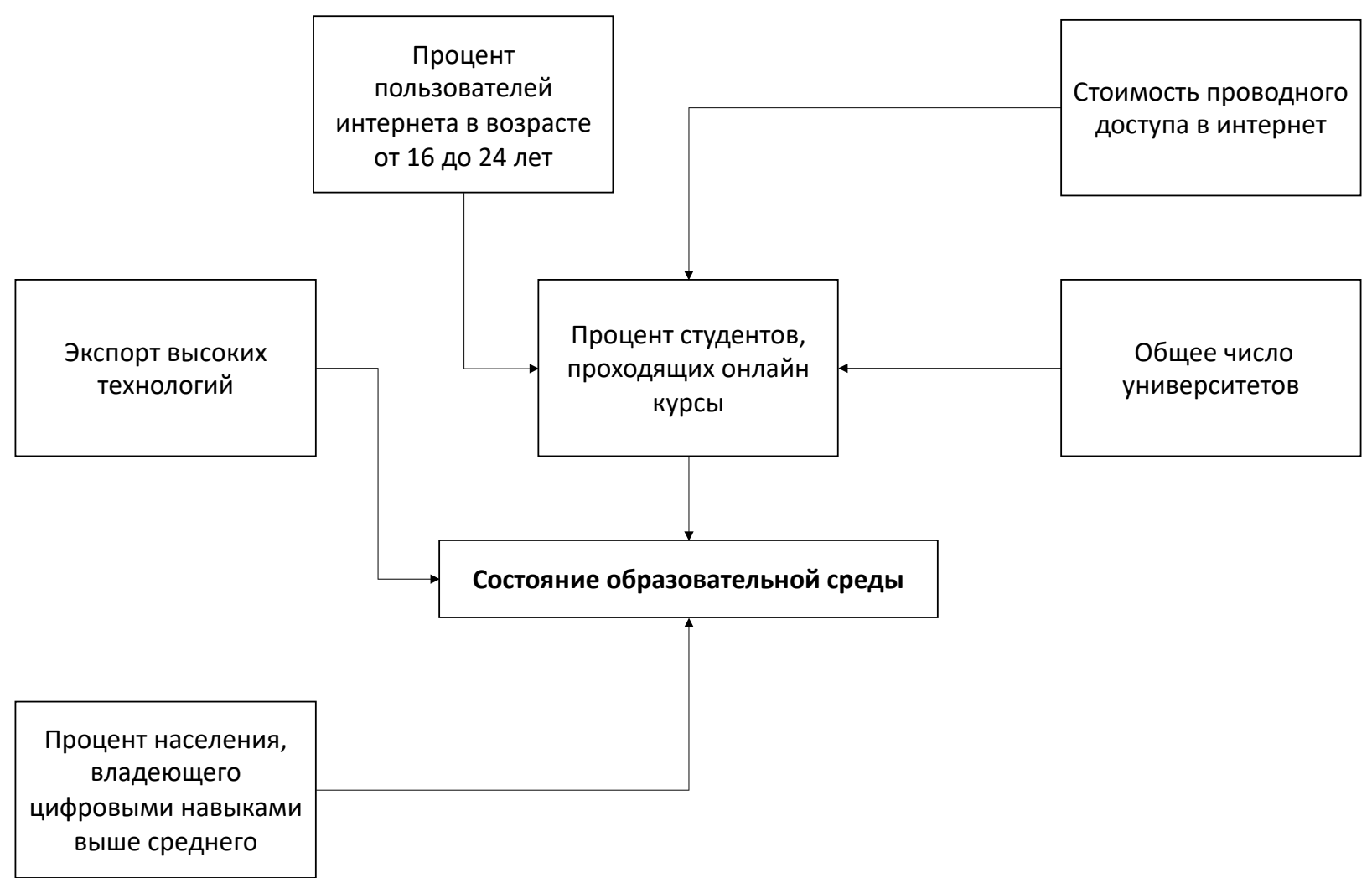

Рисунок 1. Концептуальная модель исследования

сового результата, но не к достижению общего результата - качественного и социально эффективного образования; 2) экономическое поведение субъектов-участников процесса имеет свои проблемы в социально-экономической системе современного развития страны, что ведет к дисбалансу регулирования качества процесса дистанционного обучения; 3) финансовая доктрина управляющего блока вуза - получение денег любой ценой - ведет к неэффективности самого вуза.

Таким образом, проведенный анализ литературы авторства российских и зарубежных ученых показал основные концептуальные направления влияния информационной среды и технологического развития на состояние образовательной среды высшего учебного заведения.
Для математической оценки данного процесса автором был выбран метод регрессионного анализа.

В качестве независимых переменных будут использованы данные по экспорту высоких технологий населению, владеющему цифровыми навыками выше среднего уровня, а также процент студентов, проходящих онлайн курсы. Кроме того, рассмотрено влияние индекса развития ИКТ и стоимости проводного доступа в интернет. Как упоминалось раннее, недоступность Интернета, а также слаборазвитая сфера информационно-коммуникационных технологий пагубно сказываются на динамике уровня образования, ограничивая доступ прогрессивным подходам к улучшению образовательной среды.

\section{Библиографический список}

1. Фундаментальные и прикладные научные исследования: актуальные вопросы, достижения и инновации: сборник статей XIV Международной научно-практической конференции: в 2 ч., Пенза, 15 августа 2018 года.-Пенза: «Наука и Просвещение» (ИП Гуляев Г. Ю.), 2018. - 230 с. - ISBN 978-5-907103-58-0.

2. Lambrechts, Wynand \& Sinha, Saurabh. (2019). Limitations of Last Mile Internet Access in Developing Countries. 10.1007/978-3-030-20957-5_2. 
3. Billon, Margarita \& Crespo, Jorge \& Lera-Lopez, Fernando. (2021). Do educational inequalities affect Internet use? An analysis for developed and developing countries. Telematics and Informatics. 58. 101521. 10.1016/j. tele.2020.101521.

4. James, Jeffrey. (2010). Mechanisms of access to the Internet in rural areas of developing countries. Telematics and Informatics. 27. 370-376. 10.1016/j.tele.2010.02.002.

5. López-Sintas, Jordi \& Lamberti, Giuseppe \& Sukphan, Jakkapong. (2020). The social structuring of the digital gap in a developing country. The impact of computer and internet access opportunities on internet use in Thailand. Technology in Society. 63. 101433. 10.1016/j.techsoc.2020.101433.

6. Burbules, Nicholas \& Fan, Guorui \& Repp, Philip. (2020). Five Trends of Education and Technology in a Sustainable Future. Geography and Sustainability. 1. 10.1016/j.geosus.2020.05.001.

7. Chiu, Yen-Lin \& Liang, Jyh-Chong \& Tsai, Chin-Chung. (2016). Exploring the roles of education and Internet search experience in students' Internet-specific epistemic beliefs. Computers in Human Behavior. 62. 286-291. 10.1016/j. chb.2016.03.091.

8. Chang, Sun \& Yang, Eunjin \& Lee, Kyoung-Eun \& Ryu, Hyunju. (2020). Internet health information education for older adults: A pilot study. Geriatric Nursing. 42.10.1016/j.gerinurse.2020.10.002.

9. Orim, Stella-Maris \& Nting, Rexon \& Asongu, Simplice. (2019). Inequality, Information Technology, and Inclusive Education in Sub-Saharan Africa. Technological Forecasting and Social Change. 146. 380-389. 10.1016/j. techfore.2019.06.006.

10. Bouton, Edith \& Bar-Tal, Smadar \& Asterhan, Christa. (2020). Students, Social Network Technology and Learning in Higher Education: Visions of Collaborative Knowledge Construction vs. the Reality of Knowledge Sharing. The Internet and Higher Education. 10.1016/j.iheduc.2020.100787.

11. Zhao, Danqing \& Zhong, Huaqian \& Wu, Yingli \& Zhou, Qianfu. (2020). A Study of the Impact of Internet-Based Instruction Integrated Innovation Education on University Student Entrepreneurial Team Collaboration and Strategic Innovation. Frontiers in Psychology. 11. 10.3389/fpsyg.2020.01264.

12. Tavares, Rita \& Laranjeiro, Dionisia \& Oliveira, David \& Ferraz, Clarice \& Pombo, Lúcia. (2016). Distance Education in Higher Education using Internet. Educação, Formação \& Tecnologias. 9. 29-47.

13. Богданова А.В., Коростелев А.А. Анализ и програмирование учебного поведения студентов, обучающихся дистанционно // АНИ: педагогика и психология. 2018. № 3 (24). Режим доступа: https://cyberleninka.ru/ article/n/analiz-i-programirovanie-uchebnogo-povedeniya-studentov-obuchayuschihsya-distantsionno

14. Данилова Н. Н., ХолинаИ.М. Дистанционные технологии в обучении: социальный, психологический и образовательный аспекты // Вестник Московского государственного лингвистического университета. Образование и педагогические науки. 2015. № 16 (727). Режим доступа: https://cyberleninka.ru/article/n/ distantsionnye-tehnologii-v-obuchenii-sotsialnyy-psihologicheskiy-i-obrazovatelnyy-aspekty

15. Хрянин Е. Л., Швецов А. Н. Программный агент определения психологического состояния обучаемого в системах дистанционного обучения // Программные продукты и системы. 2017. № 1. Режим доступа: https:// cyberleninka.ru/article/n/programmnyy-agent-opredeleniya-psihologicheskogo-sostoyaniya-obuchaemogo-vsistemah-distantsionnogo-obucheniya

16. Марчук Н.Ю. Психолого-педагогические особенности дистанционного обучения // Педагогическое образование в России. 2013. № 4. Режим доступа: https://cyberleninka.ru/article/n/psihologo-pedagogicheskieosobennosti-distantsionnogo-obucheniya

17. Козлова Д. А. Дистанционное обучение как инновационный подход в реализации непрерывного образования // Вестник Таганрогского института имени А.П. Чехова. 2013. № 1с. Режим доступа: https://cyberleninka. $\mathrm{ru} /$ article/n/distantsionnoe-obuchenie-kak-innovatsionnyy-podhod-v-realizatsii-nepreryvnogo-obrazovaniya

18. Шелудько Ю.Е. Отношение преподавателей разных возрастных групп к дистанционному обучению как фактор, влияющий на успешность его внедрения в учебный процесс // Вестник КГПУ им. В.П. Астафьева. 2015. № 4 (34). Режим доступа: https://cyberleninka.ru/article/n/otnoshenie-prepodavateley-raznyh-vozrastnyhgrupp-k-distantsionnomu-obucheniyu-kak-faktor-vliyayuschiy-na-uspeshnost-ego-vnedreniya-v

19. Деева С.А. Психолого-педагогические аспекты подготовки бакалавров при дистанционном обучении // Профессиональное образование в России и за рубежом. 2013. № 4 (12). Режим доступа: https://cyberleninka. ru/article/n/psihologo-pedagogicheskie-aspekty-podgotovki-bakalavrov-pri-distantsionnom-obu-chenii

20. Петухова Е.А. Психолого-педагогическое сопровождение студентов при работе с системой дистанционного обучения Moodle // МНКО. 2014. № 2 (45). Режим доступа: https://cyberleninka.ru/article/n/psihologopedagogicheskoe-soprovozhdenie-studentov-pri-rabote-s-sistemoy-distantsionnogo-obucheniya-moodle 
21. Алещенко А.С., Трембач В.М., Трембач Т.Г. Системы дистанционного обучения и их развитие с использованием когнитивных механизмов // Открытое образование. 2018. № 5. Режим доступа: https://cyberleninka. $\mathrm{ru} /$ article/n/sistemy-distantsionnogo-obucheniya-i-ih-razvitie-s-ispolzovaniem-kognitivnyh-mehanizmov

22. Яницкий М. С. Психологические аспекты цифрового образования // Профессиональное образование в России и за рубежом. 2019. № 2 (34). Режим доступа: https://cyberleninka.ru/article/n/psihologicheskie-aspektytsifrovogo-obrazovaniya

23. Ахмадиева Л.Р. Психолого-педагогические сложности реализации инновационных подходов в системе высшего образования // Вестник Московского государственного лингвистического университета. Образование и педагогические науки. 2018. № 5 (813). Режим доступа: https://cyberleninka.ru/article/n/psihologopedagogicheskie-slozhnosti-realizatsii-innovatsionnyh-podhodov-v-sisteme-vysshego-obrazovaniya

24. Чванова М.В., КиселеваИ.А. Проблемы дистанционного обучения в сети Интернет // Вестник российских университетов. Математика. 2017. № 5-2. Режим доступа: https://cyberleninka.ru/article/n/problemydistantsionnogo-obucheniya-v-seti-internet

25. Кармановский A.B. Педагогические условия формирования готовности студента вуза к непрерывному профессиональному образованию в условиях дистанционного обучения // Гуманизация образования. 2011. № 2. Режим доступа: https://cyberleninka.ru/article/n/pedagogicheskie-usloviya-formirovaniya-gotovnostistudenta-vuza-k-nepreryvnomu-professionalnomu-obrazovaniyu-v-usloviyah

26. Клименских М.В., Мальцев А.В., Савельев В.В., Селиванова О.А. Психологические особенности, влияющие на качество исследовательской деятельности слушателей массовых открытых онлайн-курсов (на примере студенческой выборки) // Наука о человеке: гуманитарные исследования. 2018. № 3 (33). Режим доступа: https://cyberleninka.ru/article/n/psihologicheskie-osobennosti-vliyayuschie-na-kachestvo-issledovatelskoydeyatelnosti-slushateley-massovyh-otkrytyh-onlayn-kursov-na

27. Барбашина Э. В., Гуляевская Н.В. Дистанционное электронное обучение: минимизация сложностей // Профессиональное образование в современном мире. - 2019. - № 9 (3). - С. 2997-3008.

28. Фадеев E.В. Организационные и психологические проблемы дистанционного обучения // МНКО. 2017. № 3 (64). Режим доступа: https://cyberleninka.ru/article/n/organizatsionnye-i-psihologicheskie-problemydistantsionnogo-obucheniya

29. Zheng F., Khan N.A., Hussain S. The COVID 19 pandemic and digital higher education: Exploring the impact of proactive personality on social capital through internet self-efficacy and online interaction quality. Children and Youth Services Review, Volume 119, 2020, 105694, ISSN 0190-7409.

30. Qazi A, Naseer K, Qazi J, AlSalman H, Naseem U, Yang S, Hardaker G, Gumaei A. Conventional to online education during COVID-19 pandemic: Do develop and underdeveloped nations cope alike. Child Youth Serv Rev. 2020 Dec; 119:105582. doi: 10.1016/j.childyouth.2020.105582. Epub 2020 Oct 13. PMID: 33071406; PMCID: PMC7550864.

31. Горбатенко Д.Н. Проблемы стартового периода перехода к дистанционному обучению в условиях пандемии COVID-19 // Скиф. 2020. № 6 (46). Режим доступа: https://cyberleninka.ru/article/n/problemy-startovogoperioda-perehoda-k-distantsionnomu-obucheniyu-v-usloviyah-pandemii-covid-19

32. Олейник Е.В., Муталова Д.А., Безенкова Т.А., Мананникова А.В. Изучение проблемы адаптации студентов вуза в условиях самоизоляции к online обучению с применением дистанционных образовательных технологий // Современное педагогическое образование. 2020. № 5. Режим доступа: https://cyberleninka.ru/ article/n/izuchenie-problemy-adaptatsii-studentov-vuza-v-usloviyah-samoizolyatsii-k-on-line-obucheniyu-sprimeneniem-distantsionnyh

33. Соколовская И.Э. Социально-психологические факторы удовлетворенности студентов в условиях цифровизации обучения в период пандемии COVID-19 и самоизоляции // Цифровая социология. 2020. № 2. Режим доступа: https://cyberleninka.ru/article/n/sotsialno-psihologicheskie-faktory-udovletvorennosti-studentov-vusloviyah-tsifrovizatsii-obucheniya-v-period-pandemii-covid-19-i

34. Бахтина Н.Н., МарковскийР.Р. К проблеме временной организации учебной детельности студентов в условиях дистанционного обучения // The Scientific Heritage. 2020. № 46-4 (46). Режим доступа: https:// cyberleninka.ru/article/n/k-probleme-vrmennoy-organizatsii-uchebnoy-detelnosti-studentov-v-usloviyahdistantsionnogo-obucheniya

35. Мукова Л. А. Из практики дистанционного обучения бакалавров в вузе (социально-психологические аспекты) // Психология человека в образовании. 2020. № 2. Режим доступа: https://cyberleninka.ru/article/n/izpraktiki-distantsionnogo-obucheniya-bakalavrov-v-vuze-sotsialno-psihologicheskie-aspekty 